\section{(B) OPEN ACCESS}

\title{
The efficiency of cardiovascular risk assessment: do the right patients get statin treatment?
}

\author{
Tjeerd-Pieter van Staa, ${ }^{1,2,3}$ Liam Smeeth, ${ }^{3}$ Edmond S-W Ng, ${ }^{1,3}$ Ben Goldacre, $^{3}$ \\ Martin Gulliford ${ }^{4}$
}

\begin{abstract}
- Additional material is published online only. To view please visit the journal online (http://dx.doi.org/10.1136/ heartjnl-2013-303698).

${ }^{1}$ Clinical Practice Research Datalink, Medicines and Healthcare products Regulatory Agency, London, UK

${ }^{2}$ Division of

Pharmacoepidemiology and Clinical Pharmacology, Utrecht Institute for Pharmaceutical Sciences, Utrecht University, Utrecht,

The Netherlands

${ }^{3}$ Department of Epidemiology and Population Health, London School of Hygiene \& Tropical Medicine, London, UK

${ }^{4}$ Primary Care and Public Health Sciences, King's College London, London, UK
\end{abstract}

\section{Correspondence to}

Professor T P van Staa, Clinical Practice Research Datalink, Medicines and Healthcare products Regulatory Agency, 151 Buckingham Palace Road, London SW1W 9SZ, UK; vanstaat@gmail.com

Received 27 January 2013 Revised 7 May 2013 Accepted 9 May 2013 Published Online First 4 June 2013

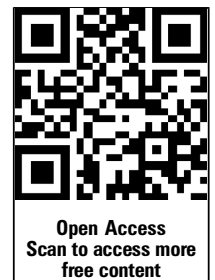

\section{SLinked}

- http://dx.doi.org/10.1136/ heartjnl-2013-304284

To cite: van Staa T-P, Smeeth L, Ng ES-W, et al. Heart 2013;99:1597-1602.

\section{ABSTRACT}

Objective To evaluate targeting of statin prescribing for primary prevention to those with high cardiovascular disease (CVD) risk.

Design Two cohort studies including the general population and initiators of statins aged 35-74 years.

Setting UK primary care records in the Clinical Practice Research Datalink.

Patients 3.8 million general population patients and 300914 statin users.

Intervention Statin prescribing.

Main outcome measures Statin prescribing by CVD risk; observed 5-year CVD risks; variability between practices.

Results Statin prescribing increased substantially over time to patients with high 10-year CVD risk ( $\geq 20 \%$ ):

$7.0 \%$ of these received a statin prior to 2007 , and $30.4 \%$ in 2007 onwards. Prescribing to patients with low risk (<15\%) also increased (from 1.9\% to $5.0 \%$ ). Only about half the patients initiating statin treatment were high risk according to CVD risk score. The 5-year CVD risks, as observed during statin treatment, reduced over calendar time (from $17.0 \%$ to $7.1 \%$ ). There was a large variation between general practices in the percentage of high-risk patients prescribed a statin in 2007 onwards, ranging from $8.2 \%$ to $61.5 \%$. For lowrisk patients, these varied from $2.1 \%$ to $29.1 \%$.

Conclusions There appeared to be substantive overuse in low CVD risk and underuse in high CVD risk (600 000 and 850000 patients, respectively, in the UK since 2007). There is wide variation between practices in statin prescribing to patients at high CVD risk. There is a clear need for randomised trials for the best strategy to target statin treatment and manage CVD risk for primary prevention.

\section{INTRODUCTION}

Cardiovascular disease (CVD) is a major cause of mortality and morbidity worldwide. It causes impaired quality of life and accounts for a large share of health services usage. ${ }^{1}$ Preventive medical interventions, including the prescription of statins, to reduce the risk of CVD in otherwise healthy individuals are an increasingly important component of medical practice. The UK National Collaborating Centre for Primary Care and Royal College of General Practitioners and National Institute of Clinical Excellence (NICE) recommended in 2007 that statins should be used '....as part of the management strategy for the primary prevention of CVD for adults who have a $20 \%$ or greater 10-year risk of developing CVD.... ${ }^{2}$ The
Joint British Societies recommended that statins should be used if there is a high total risk of developing risk of CVD and the total cholesterol and LDL cholesterol targets have not been achieved. ${ }^{3}$ In the UK, the National Health Service is introducing a population-wide vascular risk assessment programme. This consists of a systematic approach to assessing risk of vascular diseases for everyone between 40 and 74 years of age who is not yet diagnosed with CVD or treated for risk factors. ${ }^{4}$ Several risk scores (including Framingham, ASSIGN and QRISK2) can be used to estimate 10-year CVD risk. ${ }^{5-8}$

A recent review of 20 studies that evaluated different risk scores for their performance showed inconsistent results of the prognostic ability of the most popular risk scores. It concluded that the literature seems affected by optimism and recommended that performance of risk scores should be documented and tested in several studies carried out by independent researchers. ${ }^{9}$ Furthermore, the performance of the risk scores in predicting high CVD risk ( $\geq 20 \%$ over 10 years) remains uncertain, and the Framingham risk score now overestimates CVD risk for the UK population. ${ }^{10}$ The objective of this study was to evaluate the performance of the current strategy to target statin treatment based on CVD risk scores.

\section{METHODS}

\section{Data source}

This study used data from the Clinical Practice Research Datalink (CPRD) in the UK, which was formerly known as the General Practice Research Database. CPRD comprises the anonymised, computerised, medical records maintained by general practitioners (GPs) of about $8 \%$ of the UK population. GPs play a key role in the UK healthcare system, as they are responsible for primary healthcare and specialist referrals. Patients are affiliated with a practice, which centralises the medical information from the GPs, specialist referrals and hospitalisations. In the UK, the GP typically manages the prescribing for chronic diseases such as diabetes. The data recorded in the CPRD since 1987 include demographic information, prescription details, clinical events, preventive care provided, specialist referrals, hospital admissions and their major outcomes. ${ }^{11} \mathrm{~A}$ recent review of validation studies found that medical data in the CPRD were generally of high quality. ${ }^{12}$ The protocol of this study was approved by the CPRD Independent Scientific Advisory Committee. 


\section{Study populations}

The following two study populations were identified in the November 2011 version of CPRD. The first population (referred to as the general population) included patients aged 35-74 years registered in a CPRD practices. The index date was a randomly selected date between 1993 and 2011. Patients with a history prior to the index date of CVD (myocardial infarction, angina, coronary heart disease, stroke and transient ischaemic attack) or diabetes mellitus were excluded. The second population consisted of patients initiating statin treatment in 1993 or later (defined as patients with a first-ever statin prescription at least 1 year after start of CPRD data collection). Patients with a history of CVD prior to, or in the first 6 weeks after starting statin treatment, or with a history of diabetes mellitus were excluded in order to restrict the study population to primary prevention. The index date was the date of first-ever statin prescription.

\section{Cardiovascular risk scores}

The 10-year CVD risks were predicted using the three published risk scores of Framingham, ASSIGN and QRISK2. ${ }^{5-8}$ We did not analyse the Joint British Society 2 risk score ${ }^{3}$ given the similarity to the Framingham risk score. ${ }^{13}$ The 10 -year CVD risks by Framingham and ASSIGN were estimated using the publicly available risk equations. ${ }^{5} 6$ The risks predicted by QRISK2 were calculated using the commercial software program as provided by CLINRISK Limited on a fee-paying licence using the 2012 version (http://qrisk.org/index.php). Online supplementary appendix table 1 lists the risk factors used in the analyses. Multiple imputation was used for smoking status, systolic blood pressure, ratio of total serum cholesterol over high density lipoprotein (HDL) cholesterol and body mass index (BMI) that were missing in the data. We followed recent advice to include the outcome and survival time variables in the imputation models. ${ }^{14}$

In the analysis of the general population, the long-term CVD risks for non-statin users were based on the risk factors measured at the index date. For patients who had been prescribed a statin prior to this date, long-term CVD risks were based on risk factors measured at the start date of statin treatment. The reason for this is that some of the risk factors may have been modified by statin treatment (such as cholesterol and HDL). In the analysis of statin initiators, long-term CVD risks were measured at the start date of statin treatment.

\section{Descriptive analyses}

The rate of statin prescribing prior to the index date was determined in the general population. The extent of statin prescribing was measured for different categories of 10-year CVD risk as predicted by the different risk scores and also stratified by calendar year. The level of variation between practices to low-risk and high-risk patients in 2007 onwards was based on an analysis of practices that had at least 50 persons included in the analysis. As there was no information on what risk score was being used by practices in the determination of CVD risk, high-risk patients $(\geq 20 \%)$ were considered to be patients who had high risk according to least one of the published risk scores (Framingham, ASSIGN or QRISK2); low-risk patients were those with a low risk with at least one of the three published risk scores.

In the population of statin initiators, the 10-year CVD risks as predicted by one of the published risk scores were estimated at the start date of statin treatment. In addition, CVD risks during statin treatment were also estimated using Kaplan-Meier life table analyses. Patients were followed from 6 weeks after starting statin treatment up to 6 months after the date of last statin prescription or the end of data collection, whichever date came first. As only a small number of statin users was exposed for over 10 years, 5 -year risks were estimated. The risks of CVD during statin treatment can be considered to be a function of both the patient's underlying risk and the effects of statins in reducing CVD. A recent Cochrane review reported that statins reduce the risk of CVD outcomes by $26 \%$ in patients without a history of CVD. ${ }^{1}$ If statins had a similar effect in the CPRD population of statin users, the underlying CVD risks would have been $26 \%$ higher, on average, than the risks observed during statin treatment. SAS V.9.2 was used for the analyses.

\section{RESULTS}

The general population included 3.8 million patients and the statin cohort 300914 patients. The follow-up was, on average, 4 years (table 1). Information was more completely recorded for the statin users compared with the general population and women generally had more complete records compared with men. Statin users were, on average, older and more likely to be men, and had a higher prevalence of obesity compared with the general population. About half the patients initiating statins had hypertension compared with only about $10 \%$ in the general population. Cholesterol levels were higher in the statin cohort compared with the general population $(64.1 \%$ of the men initiating statins had cholesterol $\geq 6 \mathrm{mmol} / \mathrm{l}$ compared with $27.1 \%$ in the general population). Past smokers were more likely to start statins, compared with the general population. The percentage of statin users with high cholesterol levels $(\geq 6 \mathrm{mmol} / \mathrm{l})$ did not vary greatly by age (age $<55,74.2 \%$; age $\geq 55,70.9 \%$ ). A low density lipoprotein (LDL) measurement was recorded in the 1 year before starting statin in 173471 (58.0\%) patients (mean LDL $4.32 \mathrm{mmol} / \mathrm{l})$. In the 51008 patients with a repeat measurement in $6-12$ months after starting the statin, the reduction in LDL was, on average, $1.57 \mathrm{mmol} / \mathrm{l}$. In the 78347 patients with a repeat measurement in the $12-24$ months, the average LDL reduction was $1.63 \mathrm{mmol} / \mathrm{l}$.

Table 2 shows the predicted CVD risks in the general population and the extent of prior statin prescribing. The number of high-risk patients who received a statin prescription previously increased substantially over calendar time. Before 2007, 7.0\% of the high-risk patients (according to QRISK2) received a statin previously, while this increased to $30.4 \%$ in 2007 onwards. However, prescribing to low-risk patients also increased over calendar time (in patients with a CVD risk of $<15 \%$ it increased from $1.9 \%$ to $5.0 \%$ ). The absolute number of low-risk (risk $<15 \%$ ) patients receiving statins in 2007 onwards exceeded that of the high-risk patients (risk $\geq 20 \%$ ). It was found that only about half the patients initiating statin treatment were high risk according to the CVD risk scores (table 3).

There were substantive changes over calendar time in the criteria for statin initiation. Prescribing of statins to patients with high cholesterol levels $(\geq 6 \mathrm{mmol} / \mathrm{l})$ and high 10-year CVD risk ( $\geq 20 \%$ ) decreased (40.2\% in 1995 and $32.0 \%$ in 2010), as did prescribing to those with high cholesterol and below-threshold CVD risk (54.9\% and 35.8\%, respectively). On the other hand, prescribing to patients with lower cholesterol levels increased over time (from $1.5 \%$ to $18.4 \%$ for those with high CVD risk and $3.4 \%$ to $13.7 \%$ for those with below-threshold CVD risk).

There was a large variation between practices in the percentage of statin prescribing to high-risk patients, ranging in 2007 onwards from $8.2 \%$ to $61.5 \%$ (figure 1 ). Similarly, practices also varied in prescribing to low-risk patients (risk <15\%), with percentages ranging from $2.1 \%$ to $29.1 \%$. Practices with higher 
Table 1 Baseline characteristics of the general population and statin cohorts

\begin{tabular}{|c|c|c|c|c|}
\hline & \multicolumn{2}{|c|}{ General population without CVD or diabetes } & \multicolumn{2}{|l|}{ Statin users } \\
\hline & Men $(n=1890530)$ & Women $(n=1917447)$ & Men $(n=161377)$ & Women $(n=139537)$ \\
\hline \multicolumn{5}{|l|}{ Age at index date } \\
\hline Mean (sd) & $49.5(11.5)$ & $50.7(12.0)$ & $58.8(9.3)$ & $61(8.6)$ \\
\hline \multicolumn{5}{|l|}{ Duration of follow-up } \\
\hline Mean (sd) & $3.9(4)$ & $4.2(4.2)$ & $4(3.1)$ & $4.3(3.3)$ \\
\hline \multicolumn{5}{|l|}{ Ethnicity } \\
\hline White (\%) & $606447(32.1)$ & 733075 (38.2) & $71624(44.4)$ & $65291(46.8)$ \\
\hline Black (\%) & $19924(1.1)$ & $23842(1.2)$ & $873(0.5)$ & $892(0.6)$ \\
\hline Indian (\%) & $12034(0.6)$ & $13196(0.7)$ & $1146(0.7)$ & $902(0.6)$ \\
\hline Other $(\%)$ & $26514(1.4)$ & $32438(1.7)$ & $1763(1.1)$ & $1466(1.1)$ \\
\hline Unknown (\%) & $1225611(64.8)$ & $1114896(58.1)$ & $85971(53.3)$ & $70986(50.9)$ \\
\hline \multicolumn{5}{|l|}{ Body mass index } \\
\hline Low $(<20)(\%)$ & $27309(1.4)$ & $83477(4.4)$ & $1314(0.8)$ & $2930(2.1)$ \\
\hline Normal $(\geq 20-<26)(\%)$ & $379674(20.1)$ & $570312(29.7)$ & $34212(21.2)$ & $35254(25.3)$ \\
\hline Overweight ( $\geq 26)(\%)$ & $508803(26.9)$ & $559330(29.2)$ & $81066(50.2)$ & $67591(48.4)$ \\
\hline Unknown (\%) & $974744(51.6)$ & $704328(36.7)$ & 44785 (27.8) & $33762(24.2)$ \\
\hline \multicolumn{5}{|l|}{ Smoking status } \\
\hline No (\%) & $564673(29.9)$ & $821574(42.8)$ & $56895(35.3)$ & $63491(45.5)$ \\
\hline Past (\%) & $239755(12.7)$ & $230404(12.0)$ & $43588(27.0)$ & $25103(18.0)$ \\
\hline Current (\%) & $403422(21.3)$ & $364550(19.0)$ & $42204(26.2)$ & $33034(23.7)$ \\
\hline Unknown (\%) & $682680(36.1)$ & $500919(26.1)$ & $18690(11.6)$ & $17909(12.8)$ \\
\hline \multicolumn{5}{|l|}{ Systolic blood pressure } \\
\hline Recorded (\%) & $1205152(63.7)$ & $1565999(81.7)$ & $156004(96.7)$ & 136138 (97.6) \\
\hline Mean (sd) & $132.6(16.2)$ & $127.8(18.0)$ & $141.9(17.6)$ & $141.2(18.7)$ \\
\hline \multicolumn{5}{|l|}{ Cholesterol HDL ratio } \\
\hline Recorded (\%) & 336579 (17.8) & 353677 (18.4) & $123314(76.4)$ & $104198(74.7)$ \\
\hline Mean (sd) & $4.4(1.3)$ & $3.7(1.2)$ & $5.3(1.5)$ & $4.7(1.4)$ \\
\hline \multicolumn{5}{|l|}{ Cholesterol } \\
\hline Recorded (\%) & $462057(24.4)$ & $484668(25.3)$ & $146672(90.9)$ & $126441(90.6)$ \\
\hline$\geq 6 \mathrm{mmol} / /(\%)$ & $125193(27.1)$ & 150901 (31.1) & $94067(64.1)$ & 101886 (80.6) \\
\hline \multicolumn{5}{|c|}{ Number of GP records in year before } \\
\hline Mean (sd) & $10.1(15.2)$ & $16.3(18.4)$ & $25.8(18.5)$ & $32.1(21.5)$ \\
\hline Treated hypertension (\%) & $155293(8.2)$ & $191104(10)$ & $71477(44.3)$ & $65348(46.8)$ \\
\hline Atrial fibrillation (\%) & $16275(0.9)$ & $9742(0.5)$ & $5170(3.2)$ & $2751(2.0)$ \\
\hline Chronic renal disease (\%) & $14729(0.8)$ & $20943(1.1)$ & $5173(3.2)$ & $6323(4.5)$ \\
\hline Rheumatoid arthritis (\%) & $8633(0.5)$ & $21818(1.1)$ & $1452(0.9)$ & $3032(2.2)$ \\
\hline Left ventricular hypertrophy (\%) & $5907(0.3)$ & $3523(0.2)$ & $2131(1.3)$ & $1140(0.8)$ \\
\hline
\end{tabular}

levels of statin prescribing to high-risk patients tended to have higher levels of prescribing to low-risk patients.

Over 100000 patients used statins and had follow-up for over 5 years. The 5 -year observed CVD risk during statin treatment (as estimated using Kaplan-Meier life tables) was, on average, $8.9 \%$ (95\% CI $8.7 \%$ to $9.0 \%)$. There was a strong reduction in observed CVD risks over calendar time: observed 5-year risks were $17.0 \%$ (95\% CI $16.3 \%$ to $17.7 \%$ ) for patients starting statins in 1993 to $1999,12.4 \%$ (95\% CI $12.1 \%$ to $12.8 \%$ ) in $2000-2002$, $8.6 \%$ (95\% CI $8.4 \%$ to $8.8 \%$ ) in $2003-$ 2005 and $7.1 \%$ (95\% CI $6.9 \%$ to $7.3 \%$ ) in $2006-2008$.

\section{Discussion}

We found that patients at high risk of CVD were prescribed statins more frequently in recent years. However, the rate of prescribing to low-risk patients also increased. The targeting of statins to high-risk patients has become less efficient in recent years, as both the CVD risks as predicted at baseline by the risk scores and the actual risks during statin treatment have reduced over time.

\section{Use of statins in actual clinical practice}

A large number of the patients who initiated statin treatment were found to have low CVD risks as predicted by the scores. Extrapolating these numbers to the UK population, about 600000 patients may have been prescribed a statin since 2007 despite having a CVD risk below 15\% with any of the risk scores. Over 2.8 million patients received statin while having a predicted 10-year CVD risk of over 15\%. About 850000 did not receive a statin despite having a 10 -year CVD risk of over $15 \%$. The audit strategy for measuring compliance to the NICE guidance for primary CVD prevention describes the following criteria: (1) a systematic strategy is in place to identify people aged 40-74 years who are likely to be at high CVD risk, (2) there is a process to prioritise people based on an estimate of their CVD risk before undertaking full formal risk assessment (based on data recorded in the electronic health records). ${ }^{2}$ The results in this present study suggest that GPs have indeed been undertaking more CVD risk assessments (as reflected by the increases in statin prescribing and recording of risk factors) but that the approaches in how high CVD risk is assessed vary between practices. 
Table 2 Number of patients in the general population cohort with prior statin prescribing stratified by predicted 10-year CVD risks

\begin{tabular}{|c|c|c|c|c|}
\hline Risk score & Time period & $\begin{array}{l}10 \text {-year CVD risk as predicted } \\
\text { by risk score }(\%)\end{array}$ & $\begin{array}{l}\text { No prior statin use } \\
\text { n patients (\%) }\end{array}$ & $\begin{array}{r}\text { Prior statin use } \\
\text { n patients (\%) }\end{array}$ \\
\hline Framingham risk score & $\geq 2007$ & $\begin{array}{l}<5 \\
5-10 \\
10-15 \\
15-20 \\
\geq 20 \\
<5 \\
5-10 \\
10-15 \\
15-20 \\
\geq 20\end{array}$ & $\begin{array}{r}794744(99.5) \\
519859(98.1) \\
329159(96.2) \\
202504(94.6) \\
319089(92.8) \\
733476(98.6) \\
368689(94.1) \\
181755(87.9) \\
89542(80.8) \\
88469(70.3)\end{array}$ & $\begin{array}{c}3898(0.5) \\
10300(1.9) \\
12940(3.8) \\
11447(5.4) \\
24757(7.2) \\
10686(1.4) \\
22936(5.9) \\
24977(12.1) \\
21296(19.2) \\
37454(29.7)\end{array}$ \\
\hline ASSIGN risk score & $\begin{array}{l}<2007 \\
\geq 2007\end{array}$ & $\begin{array}{l}<5 \\
5-10 \\
10-15 \\
15-20 \\
\geq 20 \\
<5 \\
5-10 \\
10-15 \\
15-20 \\
\geq 20\end{array}$ & $\begin{array}{r}909040(99.4) \\
539327(97.7) \\
266315(95.3) \\
173180(94.1) \\
277493(92.9) \\
820316(98.4) \\
370639(93.0) \\
145305(84.4) \\
68952(76.7) \\
56720(66.8)\end{array}$ & $\begin{array}{c}5146(0.6) \\
12974(2.3) \\
13101(4.7) \\
10860(5.9) \\
21260(7.1) \\
13377(1.6) \\
27994(7.0) \\
26787(15.6) \\
20999(23.3) \\
28191(33.2)\end{array}$ \\
\hline QRISK2 risk score & $\begin{array}{l}<2007 \\
\geq 2007\end{array}$ & $\begin{array}{l}<5 \\
5-10 \\
10-15 \\
15-20 \\
\geq 20 \\
<5 \\
5-10 \\
10-15 \\
15-20 \\
\geq 20\end{array}$ & $\begin{array}{r}1149295(99.2) \\
354037(96.7) \\
212654(94.9) \\
172081(94.5) \\
277287(93.0) \\
969202(98.0) \\
230873(90.7) \\
117838(83.9) \\
70006(78.5) \\
74014(69.6)\end{array}$ & $\begin{array}{r}9128(0.8) \\
11927(3.3) \\
11453(5.1) \\
10014(5.5) \\
20818(7.0) \\
19526(2.0) \\
23748(9.3) \\
22529(16.1) \\
19172(21.5) \\
32374(30.4)\end{array}$ \\
\hline Any of the three risk scores (highest estimate) & $\begin{array}{l}<2007 \\
\geq 2007\end{array}$ & $\begin{array}{l}<5 \\
5-10 \\
10-15 \\
15-20 \\
\geq 20 \\
<5 \\
5-10 \\
10-15 \\
15-20 \\
\geq 20\end{array}$ & $\begin{array}{l}760603(99.6) \\
486724(98.3) \\
299741(96.4) \\
216194(95.1) \\
402093(93.2) \\
701025(98.8) \\
354980(94.9) \\
183877(89.1) \\
103799(82.8) \\
118251(72.0)\end{array}$ & $\begin{array}{c}3136(0.4) \\
8582(1.7) \\
11165(3.6) \\
11231(4.9) \\
29228(6.8) \\
8450(1.2) \\
18949(5.1) \\
22419(10.9) \\
21592(17.2) \\
45939(28.0)\end{array}$ \\
\hline
\end{tabular}

GP, general practitioner.

Table 3 10-year CVD risks as predicted by the risk scores at the start of statin treatment

\begin{tabular}{|c|c|c|c|c|c|c|c|c|}
\hline \multirow[b]{2}{*}{ Risk score } & & \multirow[b]{2}{*}{$\begin{array}{l}\text { Mean } 10 \text {-year CVD } \\
\text { risk as predicted by } \\
\text { risk score }\end{array}$} & \multirow[b]{2}{*}{$\begin{array}{l}\text { Median 10-CVD year } \\
\text { risk as predicted by } \\
\text { risk score }\end{array}$} & \multicolumn{5}{|c|}{ Categories of 10-year CVD risk as predicted by risk score } \\
\hline & & & & $\begin{array}{l}\text { Risk of } 5<\% \\
\text { Percentage of } \\
\text { patients }\end{array}$ & $\begin{array}{l}\text { Risk of } 5-10 \% \\
\text { Percentage of } \\
\text { patients }\end{array}$ & $\begin{array}{l}\text { Risk of } \\
10-15 \% \\
\text { Percentage of } \\
\text { patients }\end{array}$ & $\begin{array}{l}\text { Risk of } \\
15-20 \% \\
\text { Percentage of } \\
\text { patients }\end{array}$ & $\begin{array}{l}\text { Risk of } \geq 20 \% \\
\text { Percentage of } \\
\text { patients }\end{array}$ \\
\hline Framingham & $<2007$ & 17.7 & 15.9 & 6.9 & 19.0 & 20.6 & 18.4 & 35.1 \\
\hline ASSIGN & & 19.3 & 17.4 & 5.0 & 15.6 & 20.3 & 18.6 & 40.5 \\
\hline QRISK2 & & 17.6 & 16.2 & 10.6 & 17.2 & 17.8 & 16.9 & 37.5 \\
\hline $\begin{array}{l}\text { Any of the three risk } \\
\text { scores (highest } \\
\text { estimate) }\end{array}$ & & 21.6 & 17.4 & 3.9 & 12.3 & 16.6 & 17.7 & 49.5 \\
\hline Framingham & $\geq 2007$ & 16.8 & 15.6 & 6.7 & 18.5 & 22.2 & 20.9 & 31.7 \\
\hline ASSIGN & & 18.6 & 17.3 & 4.9 & 15.2 & 20.5 & 20.4 & 39.0 \\
\hline QRISK2 & & 17.8 & 16.6 & 9.8 & 16.1 & 18.1 & 18.0 & 38.0 \\
\hline $\begin{array}{l}\text { Any of the three risk } \\
\text { scores (highest } \\
\text { estimate) }\end{array}$ & & 21.3 & 17.3 & 3.7 & 11.2 & 16.2 & 18.8 & 50.2 \\
\hline
\end{tabular}




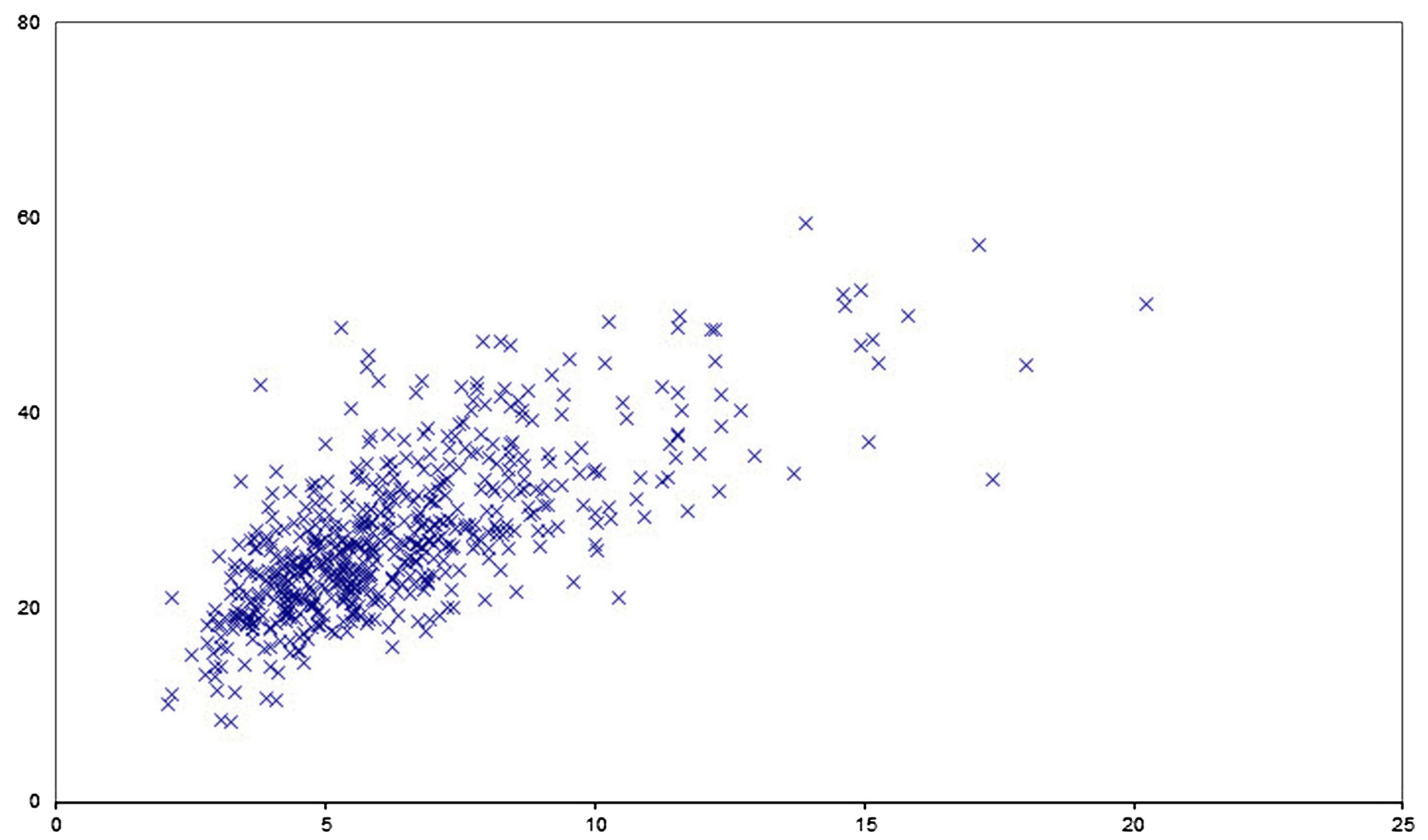

Figure 1 Percentage of patients with low risk $(<15 \%)$ or high risk $(\geq 20 \%)$ prescribed a statin in 2007 onwards, stratified by practice. $X$-axis: percentage of statin prescribing in a practice to low-risk patients. Y-axis: percentage of statin prescribing in a practice to high-risk patients. Each $X$ corresponds to one practice.

\section{Ideal approach to targeting of statins}

The real purpose of screening and risk assessment programmes, according to Geoffrey Rose, is to identify those people in whom the intervention offers the most benefit. It is not to categorise people according to their overall risk but rather to identify those who can be helped by preventive action. ${ }^{15}$ Several criteria have been proposed to assess the appropriateness of risk assessment programmes for primary prevention, including the need for evidence from randomised trials that the programme improves morbidity. ${ }^{16}$ Most randomised trials in primary prevention selected patients based on increased cholesterol or LDL levels rather than baseline CVD risk as determined by a risk score by GPs. The long-term effects of a risk assessment programme should also be measured. The lowering of treatment thresholds for CVD risk, as recently proposed, ${ }^{17}{ }^{18}$ would lead to younger people being treated. As many patients stop statin treatment within a few years (and may be unlikely to start again at a later date), there should be evidence that early treatment allows for improved health outcomes beyond what might be achieved through later treatment. ${ }^{16}$ Cluster randomised trials could be conducted to compare different strategies to target statin treatment. Practices could be randomised to different strategies, and the effects can then be measured at low cost using the routinely collected electronic healthcare records. ${ }^{19}$ Randomisation with systematic data collection is the most rational and ethical way to resolve uncertainties. $^{20}$ The clinical usefulness of these risk scores should ultimately be established on their potential for improving health outcomes. ${ }^{15}$ However, it is unlikely that such trials can easily be conducted. Bradford Hill said that interventions must be evaluated when they are first introduced, as once they are established, RCTs become difficult or impossible. ${ }^{21}$

\section{Strengths and limitations of present study}

The strength of this study was the large size and representativeness of the study population, the well-documented data quality of $\mathrm{CPRD}^{12}$ and the availability of linked hospital and death certificate data. There are several important limitations. We did not have any information on the risk score that was being used by the practices for the vascular risk screening programme, but there is no consensus or guideline from NICE on the choice of a specific risk score. Therefore, we used the three risk scores that have been evaluated in UK populations or mentioned in NICE guidelines. Our approach was to use the highest estimate of Framingham, ASSIGN or QRISK2 in assessing high CVD risk. Another limitation was that statins are available over-the-counter (OTC) introduced some years ago. OTC use is rarely recorded by GPs. This may lead to underestimation of statin exposure. However, it is unlikely that OTC use will be determined by long-term CVD risk as estimated by the risk scores. Also, medications as obtained through the GP are free for patients aged 65 years or older; thus, elderly patients may be less likely to use OTC medication for chronic use. The completeness of information was another limitation. Laboratory and physical measurements were missing for a substantive number of patients. The extent of missing data decreased substantially over time. Reasons for this include the availability of electronic communication between practices and laboratories, and the incentivisation of practices in measuring and recording of data. We applied imputation techniques but found that patients with imputed values had different CVD risks compared with those without missing data. This is not unexpected as healthy patients are less likely to visit their practice. 


\section{CONCLUSIONS}

There is large variation between practices in the extent that statins are prescribed to patients at high risk of CVD and a substantive number of patients at low risk of CVD. There appeared to be a substantive overuse in patients with low CVD risk as well as underuse in those with high CVD risk. The strategy to identify patients at high CVD risk in UK clinical practice has become less efficient following the publication of NICE guidance. There is a clear need for randomised trials for the best strategy to target statin treatment.

Correction notice This article has been changed since it was first published online. Acknowledgements The views expressed in this paper are those of the authors, and do not reflect the official policy or position of the MHRA.

Contributors TVS, MG and LS were involved in the design of the study. TVS and EN carried out the data management and statistical analysis and wrote the first draft. All authors contributed to further drafts.

Funding This study was funded by the Wellcome Trust as part of a programme to evaluate the feasibility of conducting pragmatic randomised trials within CPRD (grant WT086136MA); this work was done as part of the assessment of eligibility for a trial comparing simvastatin and atorvastatin. LS is supported by a Senior Clinical Fellowship from the Wellcome Trust. MG was supported by the National Institute for Health Research (NIHR) Biomedical Research Centre at Guy's and St Thomas' NHS Foundation Trust and King's College London.

Competing interests All authors confirm that they are not involved in any organisation or entity with a financial interest in or financial conflict with the subject matter or materials discussed in this manuscript. CPRD is owned by the UK Department of Health and operates within the Medicines and Healthcare products Regulatory Agency (MHRA). CPRD has received funding from the MHRA, Wellcome Trust, Medical Research Council, NIHR Health Technology Assessment programme, Innovative Medicine Initiative, UK Department of Health, Technology Strategy Board, Seventh Framework Programme EU, various universities, contract research organisations and pharmaceutical companies. The department of Pharmacoepidemiology \& Pharmacotherapy, Utrecht Institute for Pharmaceutical Sciences has received unrestricted funding for pharmacoepidemiological research from GlaxoSmithKline, Novo Nordisk, the private-public funded Top Institute Pharma (http://www.tipharma.nl, includes cofunding from universities, government, and industry), the Dutch Medicines Evaluation Board, and the Dutch Ministry of Health.

Ethics approval Independent Scientific Advisory Group.

Provenance and peer review Not commissioned; externally peer reviewed.

Open Access This is an Open Access article distributed in accordance with the Creative Commons Attribution Non Commercial (CC BY-NC 3.0) license, which permits others to distribute, remix, adapt, build upon this work non-commercially, and license their derivative works on different terms, provided the original work is properly cited and the use is non-commercial. See: http://creativecommons.org/licenses/by-nc/3.0/

\section{REFERENCES}

1 Taylor F, Ward K, Moore TH, et al. Statins for the primary prevention of cardiovascular disease. Cochrane Database Syst Rev 2011;(1):CD004816.
2 Cooper A, Nherera L, Calvert N, et al. Clinical Guidelines and Evidence Review for Lipid Modification: cardiovascular risk assessment and the primary and secondary prevention of cardiovascular disease. London: National Collaborating Centre for Primary Care and Royal College of General Practitioners, 2007.

3 British Cardiac Society, British Hypertension Society, Diabetes UK. JBS guidelines on prevention of CVD in clinical practice. Heart 2005;91:1-52.

4 Putting prevention first-vascular checks: risk assessment and management (April 2008) NHS Health Check Programme. ww.healthcheck.nhs.uk/document.php? $=224$

5 Anderson KM, Odell PM, Wilson PWF, et al. Cardiovascular disease risk profiles. Am Heart J 1991;121:293-8.

6 Woodward M, Brindle P, Tunstall-Pedoe H. Adding social deprivation and family history to the cardiovascular risk assessment: the ASSIGN score from the Scottish Heart Health Extended Cohort (SHHEC). Heart 2007;2:172-6.

7 Hippisley-Cox J, Coupland C, Vinogradova Y, et al. Derivation and validation of QRISK, a new cardiovascular disease risk score for the United Kingdom: prospective open cohort study. BMJ 2007;335(7611):136 doi:10.1136/bmj.39261.471806.55.

8 Hippisley-Cox J, Coupland C, Vinogradova Y, et al. Predicting cardiovascular risk in England and Wales: prospective derivation and validation of QRISK2. BMJ 2008;336:1475-82.

9 Siontis GC, Tzoulaki I, Siontis KC, et al. Comparisons of established risk prediction models for cardiovascular disease: systematic review. BMJ 2012;344:e3318.

10 Collins GS, Altman DG. Predicting the 10 year risk of cardiovascular disease in the United Kingdom: independent and external validation of an updated version of QRISK2. BMJ 2012;344:e4181.

11 Williams T, van Staa TP, Puri S, et al. Recent advances in the utility and use of the General Practice Research Database as an example of a UK Primary Care Data resource. Ther Adv Drug Saf 2012;3:89-99.

12 Herrett E, Thomas SL, Schoonen WM, et al. Validation and validity of diagnoses in the General Practice Research Database: a systematic review. Br I Clin Pharmacol 2010;69:4-14

13 National Institute for Health and Clinical Excellence. Quality and outcomes framework (QOF) indicator guidance; indicator area: primary prevention of cardiovascular disease. http://www.nice.org.uk/nicemedia/live/13520/55454/55454.pdf

14 Sterne JA, White IR, Carlin JB, et al. Multiple imputation for missing data in epidemiological and clinical research: potential and pitfalls. BMJ 2009;338:b2393.

15 Rose G. Rose's strategy of preventive medicine. New York: Oxford University Press Inc, 2008.

16 Prasad V, Vandross A. Cardiovascular primary prevention: how high should we set the bar? Archives Intern Med 2012:172:656-7.

17 Cholesterol Treatment Trialists' Ctt Collaborators. The effects of lowering LDL cholesterol with statin therapy in people at low risk of vascular disease: meta-analysis of individual data from 27 randomised trials. Lancet 2012;380 (9841):581-90.

18 Ebrahim S, Casas JP. Statins for all by the age of 50 years? Lancet 2012;380 (9841):545-7.

19 Gulliford MC, Charlton J, Ashworth M, et al. Selection of medical diagnostic codes for analysis of electronic patient records. Application to stroke in a primary care database. PLoS One 2009:4:e7168.

20 van Staa TP, Goldacre B, Gulliford M, et al. Randomised Evaluations of Accepted Choices in Treatment (REACT) trials: large-scale pragmatic trials within databases of routinely collected electronic healthcare records. BMJ 2012; 344:e55.

21 Holland WW, Breeze E, Swan AV. Clinical trials: some reflections. Stat Med 1982:1:361-8. 